\title{
Synthesis and Characterization of Porous Carbon from Petroleum Pitch Using KOH
}

\author{
C. Srinivasakannan*, Mohammad El-Mootassem, K. Suresh Kumar Reddy, Ahmed Al Shoaibi \\ Chemical Engineering Department, Khalifa University of Science and Technology, The Petroleum Institute, Abu Dhabi, UAE \\ Email: *srinivasa.chandrasekar@ku.ac.ae
}

How to cite this paper: Srinivasakannan, C., El-Mootassem, M., Reddy, K.S.K. and Al Shoaibi, A. (2018) Synthesis and Characterization of Porous Carbon from Petroleum Pitch Using KOH. Journal of Materials Science and Chemical Engineering, 6, 53-69.

https://doi.org/10.4236/msce.2018.67007

Received: March 14, 2018

Accepted: July 1, 2018

Published: July 4, 2018

\begin{abstract}
Preparation and process optimization of porous carbons using different carbon sources and activating agents are frequently and commonly reported in open literature. However, only scanty references are made on utilization of petroleum coke for conversion to high surface area porous carbon using $\mathrm{KOH}$ as the activating agent. Hence, the present work attempts a process optimization exercise to prepare high surface area porous carbon from Petroleum coke using chemical activation (KOH) utilizing design of experiments. The effect of activation temperature, petroleum coke to $\mathrm{KOH}$ ratio (KPR) and activation duration were assessed on the surface area and yield of the porous carbon. The process optimization was performed covering experimental parameters in the range of $500^{\circ} \mathrm{C}-800^{\circ} \mathrm{C}, 2-5$ and $30-120 \mathrm{~min}$. The optimal process conditions for maximizing the yield and BET surface area was identified to be an activation temperature of $639^{\circ} \mathrm{C}, \mathrm{KPR}$ of 4.5 and activation duration of 43 min, having BET surface area $1765 \mathrm{~m}^{2} / \mathrm{g}$ and yield of $89.8 \%$. However, an attempt to maximize only the BET surface area, ignoring yield has resulted with a porous carbon with maximum surface area of $2061 \mathrm{~m}^{2} / \mathrm{g}$, with the optimal process conditions being an activation temperature of $688^{\circ} \mathrm{C}$, KPR of 3.8 and activation duration of $74 \mathrm{~min}$, with the corresponding yield of only $77 \%$. The characterization of porous carbon was performed using nitrogen adsorption isotherm, FT-IR and SEM analysis.
\end{abstract}

\section{Keywords}

Petroleum Coke, Porous Carbon, $\mathrm{KOH}$ Activation, ANOVA, Optimization

\section{Introduction}

Porous carbons are well known and widely used adsorbent in industries for variety of separation applications. Even as compared with the new generation ad- 
sorbents, porous carbons still are the most preferred industrial adsorbent due to cost, availability and its suitability for different applications. A mere comparison of the volumes of different adsorbents being commercially manufactured would highlight its importance. Generally, the porous carbon manufacturing methods are either based on physical activation which are basically gasification reactions of carbon with steam $/ \mathrm{CO}_{2} /$ combination of both or based on the chemical activation methods which include dehydrating agents such as phosphoric acid, sodium hydroxide, potassium hydroxide, zinc chloride etc., the precursors for preparation of porous carbons could be either coal, lingocellulosic material or Biomass based materials. However, characteristics of porous carbon highly depend on its precursor characteristics and method of activation [1]. Among the available choice of impregnating agents, metal-based activating agents such as $\mathrm{KOH}$ are reported to be more suitable to produce highly micro porous carbons, having high adsorption capacities compared to other popular activating agents such as phosphoric acid and zinc chloride [2]. Utilization of $\mathrm{KOH}$ for preparation of porous carbon from various biomass materials such as apricot [3], Oil palm fiber [4], and Anthracite [2] are reported in open literature.

Petroleum coke is the most abundant byproduct of oil refining with over 100 million tons global production reported in the year 2010. Efforts have been directed towards petroleum coke utilization in the fields of combustion and gasification to generate electric power or produce syngas [5]. The applications for petroleum coke, however, have been limited mainly due to high Sulphur content $(-$ $6 \mathrm{wt} \%)$ and low surface area $\left(<5 \mathrm{~m}^{2} / \mathrm{g}\right)$. These limitations restrict the direct use of petroleum coke as an adsorbent or as a catalyst support material, as sulphur may poison the active sites on the catalyst. Several methods are reported to prepare porous carbon from petroleum coke [6] using $\mathrm{KOH}, \mathrm{NaOH}, \mathrm{Na}_{2} \mathrm{CO}_{3}$ and $\mathrm{K}_{2} \mathrm{CO}_{3}$. The $\mathrm{KOH}$ based activation was reported to result in high yield and surface area compared with other alkali metal hydroxides. The alkali metal hydroxides have been used effectively for bond breakage between carbons as well as between carbon and sulphur species [7]. Chemical activation of petroleum coke with $\mathrm{KOH}$ was reported to remove sulfur up to $98 \%$, with surface area of 1350 $\mathrm{m}^{2} / \mathrm{g}$ and micro porosities of $65 \%-75 \%$ of the total pore volume [8]. The addition of chemicals act as a catalyst for the pyrolysis process, inhibit tar formation, increase yield and leave behind void space within the carbon when the salts that are formed are washed out. The additive acts as a catalyst, which accelerates pyrolysis by promoting the rate of dehydration. Tars are either dehydrated by addition of the chemicals, or physically prevented from condensing on carbon surface. Furthermore, char yield increased by dehydration process due to the advantages of the chemical activation process include shorter activation duration, single step process and relatively lower temperature requirements.

Petroleum coke with surface area of $11.7 \mathrm{~m}^{2} / \mathrm{g}$ converted into porous carbon utilizing $\mathrm{KOH}$ as the activated agent having a surface area and pore volume of $692 \mathrm{~m}^{2} / \mathrm{g}, 0.264 \mathrm{cc} / \mathrm{g}$ respectively [9]. The same authors have also reported activation by $\mathrm{CO}_{2}$, steam and $\mathrm{H}_{3} \mathrm{PO}_{4}$, all having low pore volume and surface area 
under optimal process conditions as compared to $\mathrm{KOH}$ activation. Petroleum coke contains high sulfur content and other metals such as Fe and Al. These metals can interact with phosphorus and form compound species such as $\mathrm{FePO}_{4}$ and $\mathrm{Al}\left(\mathrm{PO}_{3}\right)_{3}$. Due to the formation of these compounds, $\mathrm{H}_{3} \mathrm{PO}_{4}$ activation efficiency was lost. Although, $\mathrm{KOH}$ activation is a well-known method to generate porous carbons, the activation mechanism has not been well understood due to complexity of variables and many parallel simultaneous reactions. In a general, the reaction of carbon and $\mathrm{KOH}$ starts with solid-solid reactions and then proceeds via solid-liquid reactions including the reduction of potassium $(\mathrm{K})$ to form metallic $\mathrm{K}$, the oxidation of carbon to carbon monoxide and carbonate, and other reactions among various active intermediates. $\mathrm{KOH}$ dehydrates to transform into $\mathrm{K}_{2} \mathrm{O}$ at $400^{\circ} \mathrm{C}$ and $\mathrm{K}_{2} \mathrm{O}$ then reacts with $\mathrm{CO}_{2}$ to form $\mathrm{K}_{2} \mathrm{CO}_{3}$. Then carbon is consumed by the reaction of carbon with $\mathrm{K}_{2} \mathrm{O}$ and $\mathrm{K}_{2} \mathrm{CO}_{3}$, with the emission of metallic $\mathrm{K}$ and $\mathrm{CO}$ affecting the yield. The reactions of $\mathrm{K}_{2} \mathrm{O}$ with carbon as well as $\mathrm{K}$ intercalation in pseudo graphitic layers are known to be the two important factors for developing a porous structure in carbon material. As per literature $\mathrm{KOH}$ activation seem to be the best method for producing porous carbon from petroleum coke [8].

However, as per author's knowledge process optimization of porous carbon from petroleum coke was not reported in open literature. Considering the fact there are a number of reactions that occur simultaneously during the process of activation, results based limited random experimental runs could vary vastly as compared to product generated at optimal experimental conditions. The experimental attempts reported in literature predominantly report single point experiments or assess effects of parameter varying one parameter at a time. Hence the present work attempts to assess the effect of the process variables such as activation temperature, $\mathrm{KOH} /$ Petroleum coke ratio (KPR), activation duration and to optimize the process conditions for maximizing the porous carbon yield and the BET surface area.

\section{Materials and Methods}

In this paper, petroleum coke received from Reliance Industries, India was used as the precursor. The petroleum coke was washed with deionized hot water to remove the foreign materials and dried in oven at $105^{\circ} \mathrm{C}$ for $24 \mathrm{~h}$. The dry materials were stored in a in a desiccator for further experiment. The $\mathrm{KOH}$ was purchased from sigma, USA. Double distilled water was used for all the washing purposes in the process. 35\% Aqueous $\mathrm{HCl}$ was purchased from Sigma, USA for neutralization of unreacted $\mathrm{KOH}$ in washing process. Litmus paper from Sigma, USA was used to test $\mathrm{pH}$ of filtrate.

The BET surface area, along with the pore size distribution was estimated using the standard nitrogen adsorption isotherm obtained by an Autosorb 1-C adsorption apparatus (Quanta Chrome Instruments, USA). Prior to analysis, the samples were first dried in an oven at $110^{\circ} \mathrm{C}$ overnight and were quickly placed in the sample tube. The tube was then heated to $170^{\circ} \mathrm{C}$ and was evacuated for $4 \mathrm{~h}$ 
until the pressure was less than $10^{-4}$ Torr. The BET surface area was calculated from the isotherms using multipoint Brunauer-Emmett-Teller (BET) method [10]. The Dubinin-Radushkevich (DR) equation was used to calculate the micropore volume. The total pore volume was calculated from nitrogen adsorption data as volume of liquid nitrogen at a relative pressure of approximately 0.99 to 1 [11]. Mesopore volume was calculated as the difference between total pore volume and micropore volume.

FT-IR spectra of various samples were recorded on a Nicolet 740 FT-IR spectrometer at ambient conditions using $\mathrm{KBr}$ as the diluent to identify the functional groups in the activated carbon. The samples were loaded into the sample holder and scanned in the mid IR region viz., 100 to $4000 \mathrm{~cm}^{-1}$ to generate the spectrum. A pellet made of nearly the same amount of $\mathrm{KBr}$ was used as the background. FEG-250 SEM instrument (FEI, Holland) was employed at an accumulation voltage of $30 \mathrm{KV}$ with $2.5 \mathrm{~K}$ magnification to estimate the surface pore structure of the porous carbon. The carbon, hydrogen, nitrogen, and sulfur (CHNS) content of the adsorbent samples have been evaluated employing ELEMETAR-VARIO-EL analyzer.

\section{Experimental}

\subsection{Preparation of Porous Carbon}

$1 \mathrm{~g}$ of petroleum coke was taken as the precursor and mixed with $\mathrm{KOH}$ powder at an impregnation ratio (KPR) of $2-5$. The mixture was activated in a horizontal furnace at a temperature of $500^{\circ} \mathrm{C}-800^{\circ} \mathrm{C}$ for an activation time of $30-120$ $\mathrm{min}$, in an inert atmosphere (Nitrogen flow of $150 \mathrm{~mL} / \mathrm{min}$ ). Upon completion of the each experiment, the carbonized samples were cooled to the room temperature in an inert atmosphere and washed repetitively with aqueous hydrochloric acid $(\mathrm{HCl})$ to remove ash present in the materials, followed by washing with distilled water several times until the $\mathrm{pH}$ of the filtrate was reduced to neutral. The samples were dried in oven at $105^{\circ} \mathrm{C}$ for $12 \mathrm{~h}$ to ensure complete dryness. The yield of porous carbon was estimated based on grams of bone-dry porous carbon prepared to the grams of bone-dry petroleum coke utilized for activation.

\subsection{Experimental Design and Statistical Analysis}

Response Surface Methodology (RSM) is a statistical and mathematical technique that relates experimental data to regression models, which is utilized to assess the effect of parameters and interaction among them in addition to optimizing the process conditions [12]. Box-Behnken Method (BBM) was employed in the present study, which utilized a minimum number of 15 experiments including three replicates [13]. The response variables are Yield $\left(\mathrm{Y}_{1}\right)$ and BET surface area $\left(\mathrm{Y}_{2}\right)$, whereas the independent variables are Temperature $\left(\mathrm{X}_{1}\right)$, KPR $\left(\mathrm{KOH} /\right.$ Petroleum Coke ratio) $\left(\mathrm{X}_{2}\right)$ and Activation time $\left(\mathrm{X}_{3}\right)$. Table 1 shows the upper and lower levels limits identified as " -1 " being low, " +1 " for upper and " 0 " for the center point. 
Table 1. High and low levels of factors.

\begin{tabular}{cccc}
\hline Factor & Low Level $(-1)$ & Center Point $(0)$ & High Level $(+1)$ \\
\hline Temperature $\left(\mathrm{X}_{1}\right)$ & $500^{\circ} \mathrm{C}$ & $650^{\circ} \mathrm{C}$ & $800^{\circ} \mathrm{C}$ \\
KPR $\left(\mathrm{X}_{2}\right)$ & 2 & 3.5 & 5 \\
Activation time $\left(\mathrm{X}_{3}\right)$ & 30 & 75 & 120 \\
\hline
\end{tabular}

The BBM utilizes an empirical second-order polynomial model relating the dependent and independent variables as expressed below,

$$
Y=\beta_{0}+\beta \sum_{i=1}^{n} \beta_{i} X_{i}+\sum_{i=1}^{n} \beta_{i j} X_{i} X_{j}+\sum_{i=1}^{n} \beta_{i i} X_{i}^{2}
$$

where $Y$ is the predicted response variable, $\beta_{0}$ is the constant, $\beta_{i}, \beta_{i j}$, and $\beta_{i i}$ are the linear, interaction and quadratic parameters respectively. The experimental data are analyzed using statistical software MINITAB-15 for the regression analyses and analysis of variance (ANOVA). The process optimization was performed using optimizer tool to maximize the individual objective functions $\left(\mathrm{Y}_{1}\right.$, and $\left.\mathrm{Y}_{2}\right)$.

\section{Results and Discussion}

\subsection{Regression Model}

The complete design matrixes along with the responses from the experimental results are presented in Table 2. Experimental runs 3, 8 and 11 were repeat runs at center point to determine experimental error. Porous carbon yield was found to vary from $51 \%$ - $97 \%$ whereas the, BET surface area was found to vary from $317-2010 \mathrm{~m}^{2} / \mathrm{g}$. A polynomial regression model was developed by using BBM to analyze the factors interactions and to identify the significant factors contributing to the regression model.

According to the sequential model sum of squares, were selected based on the highest order polynomials where the additional terms were significant and the models were not aliased. The final empirical equations after eliminating the insignificant parameters, relating to the dependent variables in the form of uncoded units to the \% Yield $\left(\mathrm{Y}_{1}\right)$ and BET surface area $\left(\mathrm{Y}_{2}\right)$ are given by Equations (2) and (3):

$$
\begin{gathered}
Y_{1}=-171.6+0.56 X_{1}+35.38 X_{2}+0.66 X_{3}-0.001 X_{3}^{2}-0.032 X_{1} X_{2}-0.18 X_{2} X_{3}(2) \\
Y_{2}=-14921.9+39.1 X_{1}+1419.1 X_{2}+22.7 X_{3}-187.7 X_{2}^{2}-0.2 X_{3}^{2}
\end{gathered}
$$

Positive sign in front of the terms indicates synergistic effect, whereas negative sign indicates antagonistic effect. The quality of the model developed was evaluated based on the correlation coefficient value $\left(R^{2}\right)$. The $R^{2}$ for \% Yield is 0.99 , while that for BET surface area is 0.97 validating the appropriateness of the model. The closer $\mathrm{R}^{2}$ value to unity, the better is the models ability in predicting the response.

The coefficients of the models are listed in Table 3 and Table 4 for \% Yield 
Table 2. Experimental data.

\begin{tabular}{cccccc}
\hline Run & $\mathrm{X}_{1}\left({ }^{\circ} \mathrm{C}\right)$ & $\mathrm{X}_{2}$ & $\mathrm{X}_{3}(\mathrm{~min})$ & $\mathrm{Y}_{1}(\%$ Yield $)$ & $\mathrm{Y}_{2}$ (BET Surface area) \\
\hline 1 & 800 & 3.5 & 30 & 67.17 & 1312 \\
2 & 500 & 2.0 & 75 & 68.37 & 317 \\
3 & 650 & 3.5 & 75 & 77.95 & 2004 \\
4 & 800 & 3.5 & 120 & 51.74 & 1285 \\
5 & 800 & 5.0 & 75 & 58.18 & 1423 \\
6 & 500 & 5.0 & 75 & 86.34 & 733 \\
7 & 500 & 3.5 & 30 & 82.73 & 826 \\
8 & 650 & 3.5 & 75 & 78.16 & 2010 \\
9 & 650 & 5.0 & 30 & 97.01 & 1445 \\
10 & 500 & 3.5 & 120 & 67.16 & 796 \\
11 & 650 & 3.5 & 75 & 78.52 & 1995 \\
12 & 650 & 2.0 & 30 & 68.69 & 1120 \\
13 & 650 & 5.0 & 120 & 60.08 & 1458 \\
14 & 650 & 2.0 & 120 & 80.75 & 1060 \\
15 & 800 & 2.0 & 75 & 68.60 & 1297 \\
\hline
\end{tabular}

Table 3. Estimated coefficients using response surface quadratic model for porous carbon yield.

\begin{tabular}{cccc}
\hline Term & Coefficient & $\mathrm{T}$ & $\mathrm{P}$ \\
\hline Constant & -166.22 & -12.37 & 0.000 \\
$\mathrm{X}_{1}$ & 0.56 & 16.12 & 0.000 \\
$\mathrm{X}_{2}$ & 32.90 & 13.31 & 0.000 \\
$\mathrm{X}_{3}$ & 0.65 & 8.82 & 0.000 \\
$\mathrm{X}_{1}{ }^{2}$ & 0 & -15.11 & 0.000 \\
$\mathrm{X}_{2}{ }^{2}$ & 0.35 & 1.39 & 0.222 \\
$\mathrm{X}_{3}{ }^{2}$ & -0.001 & -4.16 & 0.009 \\
$\mathrm{X}_{1} \mathrm{X}_{2}$ & -0.032 & -12.93 & 0.000 \\
$\mathrm{X}_{1} \mathrm{X}_{3}$ & 0 & 0.064 & 0.952 \\
$\mathrm{X}_{2} \mathrm{X}_{3}$ & -0.181 & -22.31 & 0.000 \\
\hline
\end{tabular}

$\mathrm{R}-\mathrm{Sq}=99.5 \%, \mathrm{R}-\mathrm{Sq}(\mathrm{adj})=99.2 \%$.

Table 4. Estimated coefficients using response surface quadratic model for Porous carbon BET Surface area.

\begin{tabular}{cccc}
\hline Term & Coefficient & $\mathrm{T}$ & $\mathrm{P}$ \\
\hline Constant & $-15,578.6$ & -11.20 & 0.000 \\
$\mathrm{X}_{1}$ & 40.2 & 11.18 & 0.000 \\
$\mathrm{X}_{2}$ & 1608.3 & 6.28 & 0.002 \\
$\mathrm{X}_{3}$ & 21.7 & 2.83 & 0.037 \\
$\mathrm{X}_{1}^{2}$ & 0 & -10.79 & 0.000 \\
$\mathrm{X}_{2}^{2}$ & -187.7 & -7.14 & 0.001 \\
$\mathrm{X}_{3}^{2}$ & -0.2 & -5.24 & 0.003 \\
$\mathrm{X}_{1} \mathrm{X}_{2}$ & -0.3 & -1.28 & 0.258 \\
$\mathrm{X}_{1} \mathrm{X}_{3}$ & 0 & 0.013 & 0.990 \\
$\mathrm{X}_{2} \mathrm{X}_{3}$ & 0.3 & 0.321 & 0.761
\end{tabular}

$\mathrm{R}-\mathrm{Sq}=97.4 \%, \mathrm{R}-\mathrm{Sq}(\mathrm{adj})=95.5 \%$. 
and BET surface respectively. Statistically lower the $\mathrm{p}$ value or higher the $\mathrm{F}$ value more significant is the model parameters. Table 3 shows the linear terms $\mathrm{X}_{1}, \mathrm{X}_{2}$, $\mathrm{X}_{3}$, Square term $\mathrm{X}_{1}^{2}, \mathrm{X}_{3}^{2}$, and interaction term $\mathrm{X}_{1} \mathrm{X}_{2}, \mathrm{X}_{2} \mathrm{X}_{3}$ to be significant on $\%$ Yield, while Table 4 shows all the interaction terms $\mathrm{X}_{1} \mathrm{X}_{2}, \mathrm{X}_{1} \mathrm{X}_{3}$ and $\mathrm{X}_{2} \mathrm{X}_{3}$ to be insignificant for BET Surface area at a level of $5 \%$ significance. A test on appropriateness of the model is mandatory as it is used to optimize the process conditions.

\subsection{Analysis of Variance (ANOVA)}

The validity of model in addition to $\mathrm{R}^{2}$ is based on the ANOVA, which is a statistical technique that subdivides the total variation in a set of data into component parts associated with specific sources of variation for the purpose of testing hypotheses on the parameters of the model. Table 5 shows the ANOVA results on the \% Yield. The model "F" value of 179.7 and Prob $>$ F of 0 indicates that the model is significant. Among the model parameters, Square term $\mathrm{X}_{2}{ }^{2}$, and interaction term $\mathrm{X}_{1} \mathrm{X}_{3}$ were found to be insignificant. Table 6 shows the ANOVA results of the BET Surface area. The model "F" value of 28.6 and Prob $>$ F of 0

Table 5. Analysis of variance (ANOVA) for the RSM model for Porous carbon yield.

\begin{tabular}{cccccc}
\hline Source & $\begin{array}{c}\text { Degree of freedom } \\
(\mathrm{DF})\end{array}$ & $\begin{array}{c}\text { Sum of squares } \\
(\mathrm{SS})\end{array}$ & $\begin{array}{c}\text { Mean squares } \\
(\mathrm{MS})\end{array}$ & $\mathrm{F}$ & $\mathrm{P}$ \\
\hline Model & 9 & 1949.9 & 216.7 & 179.73 & 0.000 \\
Linear & 3 & 852.9 & 156.9 & 130.14 & 0.000 \\
Square & 3 & 295.6 & 98.5 & 81.72 & 0.005 \\
Interaction & 3 & 801.5 & 267.2 & 221.63 & 0.007 \\
Error & 5 & 6.0 & 1.2 & - & - \\
Lack of fit & 3 & 5.9 & 1.9 & 23.51 & 0.041 \\
Pure error & 2 & 0.2 & 0.08 & - & - \\
Total & 14 & 1955.9 & & & \\
\hline
\end{tabular}

Table 6. Analysis of variance (ANOVA) for the RSM model for Porous carbon BET Surface area.

\begin{tabular}{cccccc}
\hline Source & $\begin{array}{c}\text { Degree of freedom } \\
\text { (DF) }\end{array}$ & $\begin{array}{c}\text { Sum of squares } \\
(\text { SS })\end{array}$ & $\begin{array}{c}\text { Mean squares } \\
(\mathrm{MS})\end{array}$ & F & P \\
\hline Model & 9 & $3,324,403$ & 369,378 & 28.59 & 0.001 \\
Linear & 3 & $1,075,883$ & 609,328 & 47.16 & 0.000 \\
Square & 3 & $2,226,160$ & 742,053 & 57.43 & 0.000 \\
Interaction & 3 & 22,359 & 7453 & 0.58 & 0.655 \\
Error & 5 & 64,600 & 12,920 & - & - \\
Lack of fit & 3 & 64,486 & 21,495 & 377.11 & 0.003 \\
Pure error & 2 & 114 & 57 & - & - \\
Total & 14 & $3,389,003$ & & & \\
\hline
\end{tabular}


indicate the appropriateness and validity of the model. Among the model parameters, all the interaction parameters were found to be insignificant. From the ANOVA results it can be concluded that the model predictions using Equations (2) and (3) are satisfactory and that the model can be utilized to identify the optimum process conditions.

\subsection{Activation Mechanism}

In the activation process a significant amount of $\mathrm{K}_{2} \mathrm{CO}_{3}$ and $\mathrm{H}_{2}$ were produced in comparison to the small amount of $\mathrm{CO}_{2}$ during the activation, which implied that most of the carbon consumption was due to the reaction of $\mathrm{K}_{2} \mathrm{O}$ with $\mathrm{CO}_{2}$ to form $\mathrm{K}_{2} \mathrm{CO}_{3}$ [14]. The presence of $\mathrm{K}_{2} \mathrm{CO}_{3}$ was found to take place at temperatures around $570^{\circ} \mathrm{C}[15]$. This sequence of reactions is shown below:

$$
\begin{gathered}
2 \mathrm{KOH} \rightarrow \mathrm{K}_{2} \mathrm{O}+\mathrm{H}_{2} \mathrm{O} \text { (Dehydration) } \\
\mathrm{C}+\mathrm{H}_{2} \mathrm{O} \rightarrow \mathrm{H}_{2}+\mathrm{CO} \text { (Water-gas Reaction) } \\
\mathrm{CO}+\mathrm{H}_{2} \mathrm{O} \rightarrow \mathrm{H}_{2}+\mathrm{CO}_{2} \text { (water-gas shift reaction) } \\
\mathrm{K}_{2} \mathrm{O}+\mathrm{CO}_{2} \rightarrow \mathrm{K}_{2} \mathrm{CO}_{3} \text { (Carbonate Formation) }
\end{gathered}
$$

At higher activation temperatures, the reduction of $\mathrm{K}_{2} \mathrm{O}$ by Carbon and $\mathrm{Hy}-$ drogen takes place to produce Metal Potassium:

$$
\begin{gathered}
\mathrm{K}_{2} \mathrm{O}+\mathrm{C} \rightarrow \mathrm{CO}+2 \mathrm{~K} \text { (Reduction by Carbon) } \\
\mathrm{K}_{2} \mathrm{O}+\mathrm{H}_{2} \rightarrow 2 \mathrm{~K}+\mathrm{H}_{2} \mathrm{O} \text { (reduction by hydrogen) }
\end{gathered}
$$

An overall reaction of the above reactions, which showed to be thermodynamically stable according to Gibbs energy calculations [15]:

$$
6 \mathrm{KOH}+\mathrm{C} \rightarrow 2 \mathrm{~K}+3 \mathrm{H}_{2}+2 \mathrm{~K}_{2} \mathrm{CO}_{3}
$$

The metallic $\mathrm{K}$ becomes mobile at activation temperatures and can intercalate into the carbon matrix, which causes a widening of the carbon layers, which results in pore formation [14].

To summarize how activation by $\mathrm{KOH}$ takes place, three main methods take place [16]:

1) Chemical activation which involves redox reactions between Potassium compounds and the carbon material which results in the formation of a porous structure.

2) Physical activation by the formation of $\mathrm{CO}_{2}$ and $\mathrm{H}_{2} \mathrm{O}$ which further contributed to the pore structure development by carbon gasification.

3) Carbon lattice expansion by metallic Potassium, which has the capability of intercalating into the carbon lattice resulting in expansion of the lattice. Once the Potassium and its compounds were washed out, they left behind pores, which increased the porosity.

\section{4. \% Yield}

The effect of activation temperature, KPR, and activation time on the \% Yield of porous carbon $\left(\mathrm{Y}_{1}\right)$ is presented in this section. Figure 1 shows the 3D surface plot of $\%$ Yield of porous carbon with respect to the activation temperature and 


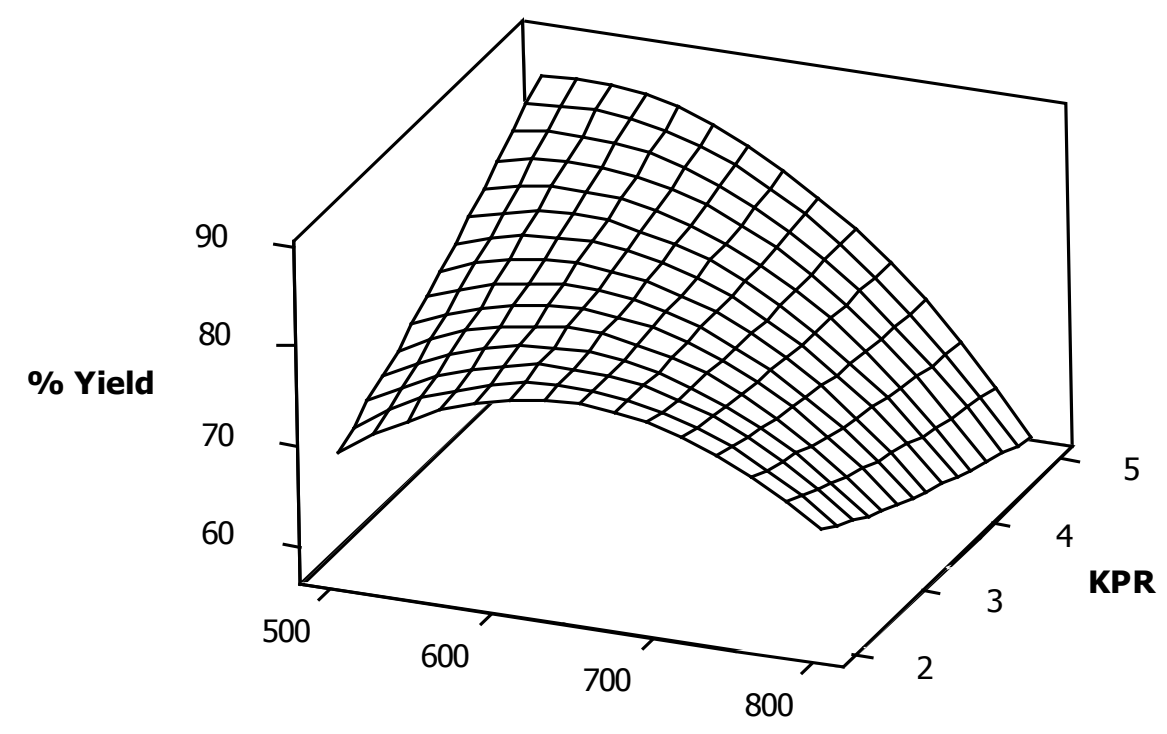

Activation temperature

Figure 1. 3D- surface plot of Activation temperature and KPR on \% Porous carbon yield $\left(\mathrm{Y}_{1}\right)$.

KPR while Figure 2 shows the three-dimensional surface plot of the effect of activation temperature and activation time on \% Yield of porous carbon, while the other parameter was held at the mid-range. The figures indicate activation temperature to be the most significant parameter having greater effect on the porous carbon \% Yield. The \% Yield was found to significantly decrease with increasing activation temperature, activation time and KPR. The effect activation time is marginal compared to activation temperature and KPR effect.

Nevertheless, from Figure 1 it can be observed that a slight increase in \% Yield from $500^{\circ} \mathrm{C}$ to $600^{\circ} \mathrm{C}$ and then decreases further until $800^{\circ} \mathrm{C}$ at lower KPR. In the first region observed low yield at $500^{\circ} \mathrm{C}$ due to the lack of formation of $\mathrm{K}$ and $\mathrm{K}_{2} \mathrm{CO}_{3}$ in the porous carbon which will form above $570^{\circ} \mathrm{C}$ (Equation (17)). But as activation temperature reaches around $600^{\circ} \mathrm{C}$, these $\mathrm{K}$ and $\mathrm{K}_{2} \mathrm{CO}_{3}$ forms and intercalate in the porous carbon which will enhance porous carbon yield, but as further temperature increases, decomposition of $\mathrm{K}_{2} \mathrm{CO}_{3}$ and elution of $\mathrm{K}$ from porous structure will take place which reduces porous carbon yield. At high activation temperatures, the carbon burn-off and coalition of micro pores will take place and subsequently porous carbon yield will decrease further. At high KPR, the \% Yield decreases continuously as temperature increases, due to the high availability of $\mathrm{K}_{2} \mathrm{O}\left(\sim 400^{\circ} \mathrm{C}\right), \mathrm{K}_{2} \mathrm{CO}_{3}\left(\sim 570^{\circ} \mathrm{C}\right)$ which will decompose and elute from the porous carbon structure and decreases porous carbon yield.

The highest yield corresponds to the minimum to medium of all three variables covered in the present work. Similar results were reported in preparation of porous carbon from coconut husk [17], oil palm fiber [4] and apricot stones [3]. The increase in activation temperature would release increasing volatiles as result of intensifying dehydration and also increased $\mathrm{C}-\mathrm{KOH}$ reaction rate, thereby decreasing the carbon yield may occurred [18]. 


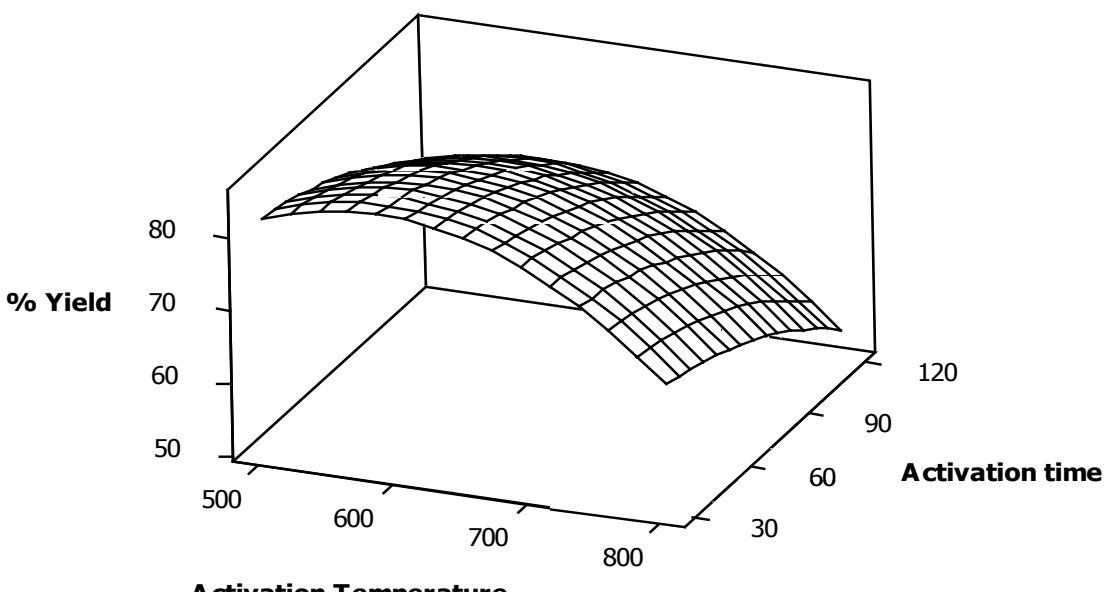

Activation Temperature

Figure 2. 3D-surface plot of Activation Temperature and Activation time on \% Porous carbon yield $\left(\mathrm{Y}_{1}\right)$.

\subsection{BET Surface Area}

BET surface area is an important parameter which determines the adsorption capacity of porous carbon. In general higher the BET surface area, higher will be the adsorption capacity provided the pore size are suitable to the adsorbing molecule. The effect of activation temperature, activation time and KPR ratio on BET Surface area $\left(\mathrm{Y}_{2}\right)$ is presented in this section. All parameters show significant effect towards BET surface area as shown in Table 4. Figure $\mathbf{3}$ shows a 3D surface plot showing effect of activation temperature and KPR on BET surface area, Figure 4 shows a 3D- surface plot of Activation temperature and Activation time on Porous carbon BET surface area $\left(\mathrm{Y}_{2}\right)$. From the list of data compiled in Table 2, the maximum surface area of $2010 \mathrm{~m}^{2} / \mathrm{g}$, corresponds to $650^{\circ} \mathrm{C}$, activation time of 75 minutes and KPR of 3.5. The BET surface area shows an increasing trend with the increase in activation temperature and KPR, until an optimal condition for both the parameters, clearly indicating the need for identifying the optimal process conditions. The decrease in BET surface area beyond the optimal condition could be attributed to the reduction in pore volume either due to pore enlargement or pore merger due to the destruction of the wall separating each pore. Considering the reaction of carbon with $\mathrm{KOH}$, the rate of reaction is bound to increase both with concentration as well as temperature contributing to the variation in the porous structure. The integration of smaller proportion of mesopores in the larger proportion of micropores generates a framework of interconnected pore networks maintaining the original textural properties. Similar results were reported for oil palm fiber-based activated carbon using $\mathrm{KOH}$ as an activating agent [4]. With increase in the KPR an increased catalytic oxidation could also cause widening of micropores to mesopores and subsequently low surface area.

\subsection{Process Optimization}

An increase in the activation temperature as well as the KPR ratio contributes to 


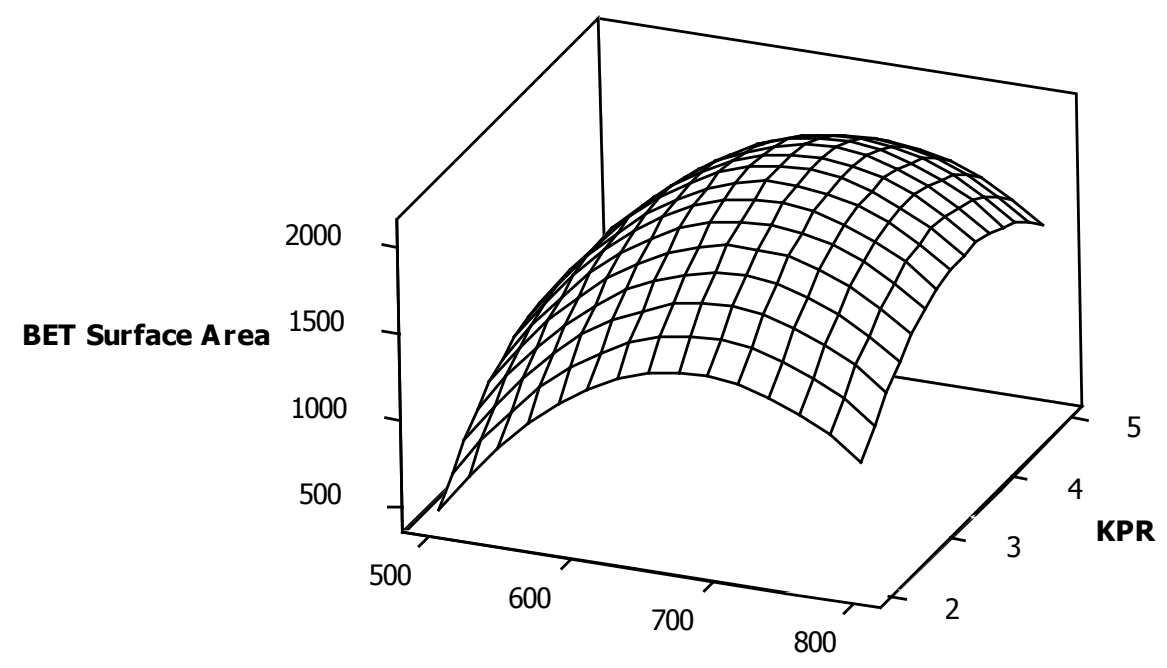

Activation temperature

Figure 3. 3D-surface plot of Activation temperature and KPR on Porous carbon BET Surface area $\left(\mathrm{Y}_{2}\right)$.

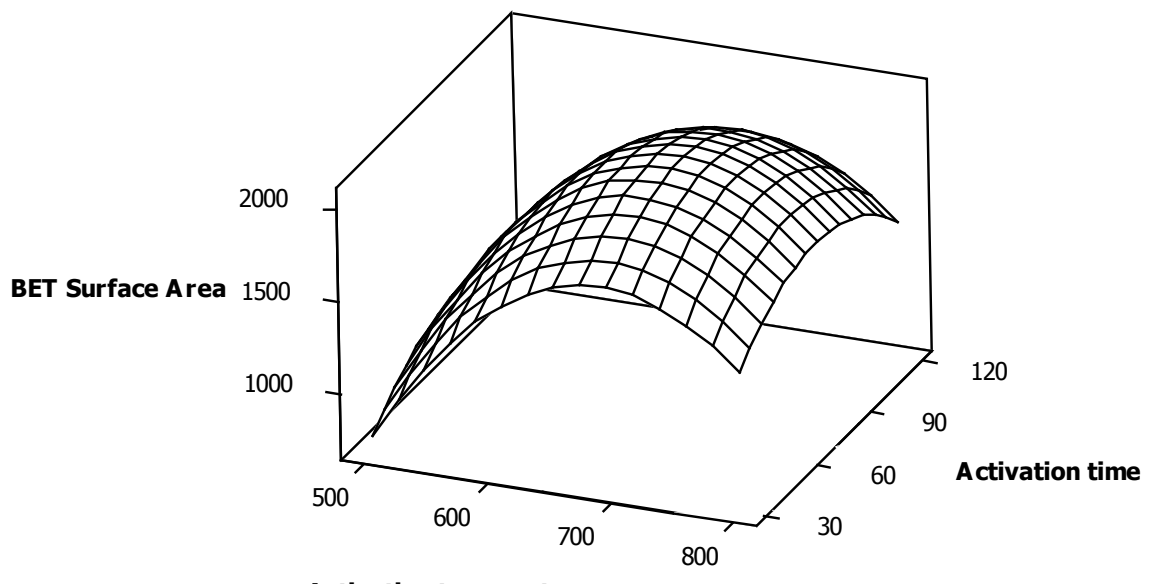

Activation temperature

Figure 4. 3D-surface plot of Activation temperature and Activation time on Porous carbon BET surface area $\left(\mathrm{Y}_{2}\right)$.

an increase in the BET surface area while it contributes to the decrease in yield of porous carbon. However, in the interest of the commercial manufacturing process, it is desirable identify the optimum condition that maximizes the yield as well as the BET surface area. Therefore, in order to compromise between these two responses, the function of desirability was applied using Design of Experiment Software (Minitab-16, USA). The optimum process conditions are estimated to be an activation temperature of $639^{\circ} \mathrm{C}$, KPR of 4.5 and activation time $43 \mathrm{~min}$, with the resultant porous carbon BET surface area $1765 \mathrm{~m}^{2} / \mathrm{g}$ and yield of $89.8 \%$. In order to ensure the acceptability of the identified optimized conditions, results of the experimental repeat runs conducted at the optimized conditions are reported in Table 7. Taking into consideration the variations involved in experiments as well as the analysis, results are in good agreement with the model prediction, validating the appropriateness of the process optimization 
Table 7. Model validation.

\begin{tabular}{|c|c|c|c|c|c|c|c|c|}
\hline \multirow{2}{*}{$\mathrm{X}_{1}$} & \multirow{2}{*}{$\mathrm{X}_{2}$} & \multirow{2}{*}{$\mathrm{X}_{3}$} & \multicolumn{2}{|c|}{$\%$ Yield } & \multirow{2}{*}{ \% Error } & \multicolumn{2}{|c|}{ BET Surface Area } & \multirow{2}{*}{ \% Error } \\
\hline & & & Predicted & Experimental & & Predicted & Experimental & \\
\hline 639.4 & 4.5 & 42.7 & 90.5 & 89.8 & 0.8 & 1739 & 1765 & 1.5 \\
\hline
\end{tabular}

exercise. It also confirms that the RSM approach is most suitable for optimization of process conditions for preparation of porous carbon.

The present work clearly confirms that all the process parameters are effective on BET surface area and \% Yield of porous carbon. In general optimum process conditions vary depending on the type of precursor [19]. In general based on a clear review of the literature, it can be concluded that the optimal KPR ratio could vary from 2 - 5 depending on the type of petroleum coke precursor and an increase in KPR ratio could contribute to a decrease in the micro pore volume due to coalescence of pores [20].

\subsection{Characterization of Porous Carbon}

The structural heterogeneity of porous carbon is very important for all adsorption processes. Figure 5 shows the adsorption desorption isotherm of $\mathrm{N}_{2}$ at -196 $\mathrm{K}$ for sample prepared at the optimum conditions. A sharp increase in the adsorption curve at $\mathrm{P} / \mathrm{P}_{0}$ value of 0.1 is indicative of the fact that micropores are being filled and therefore high uptakes are observed at relatively low pressures, because of the narrow pore width and the high adsorption potential. The figure shows a slight steep increase in the isotherm at a high relative pressure could indicate capillary condensation in the mesopores [21]. It has been reported that porous carbon prepared at high activation temperature and KPR possess a mixture of both micro and mesopores [22].

The BET surface area of the porous carbon is estimated as $2010 \mathrm{~m}^{2} / \mathrm{g}$, with average pore volume of $0.85 \mathrm{cc} / \mathrm{g}$, and average pore diameter of $1.42 \mathrm{~nm}$, with the proportion of micropore volume being $0.76 \mathrm{cc} / \mathrm{g}$ with $89.4 \%$ in total pore size distribution as shown in Table 8. The high proportion of micro pore volume and the low average pore diameter vouch the micropore nature of the carbon indicating the ability of the $\mathrm{KOH}$ activation to produce more micro porous carbon as reported in literature. Figure 6 shows the Pore Size Distribution of porous carbon, which indicates large proportion of pores in the micropore region, however with the lesser proportion of pores covering a wide range of mesopores.

In order to further investigate their surface chemistries, FT-IR spectra of porous carbon is presented in Figure 7. The FT-IR spectrum of the precursor shows the presence of functional groups such as alkene, ester, aromatic, ketone, alcohol, hydroxyl, ether and carboxyl. This is in accordance with the date palm seeds composed of cellulose, hemicellulose and lignin [10] [23]. The spectrum of porous carbon shows IR bands around $3400-3600 \mathrm{~cm}^{-1}$ that could be attributed to $\mathrm{COOH}$ or $-\mathrm{OH}$ vibration stretching of hydroxyl groups involved in hydrogen bonding possibly due to adsorbed water [24]. The band at $1640 \mathrm{~cm}^{-1}$ ascribed to 


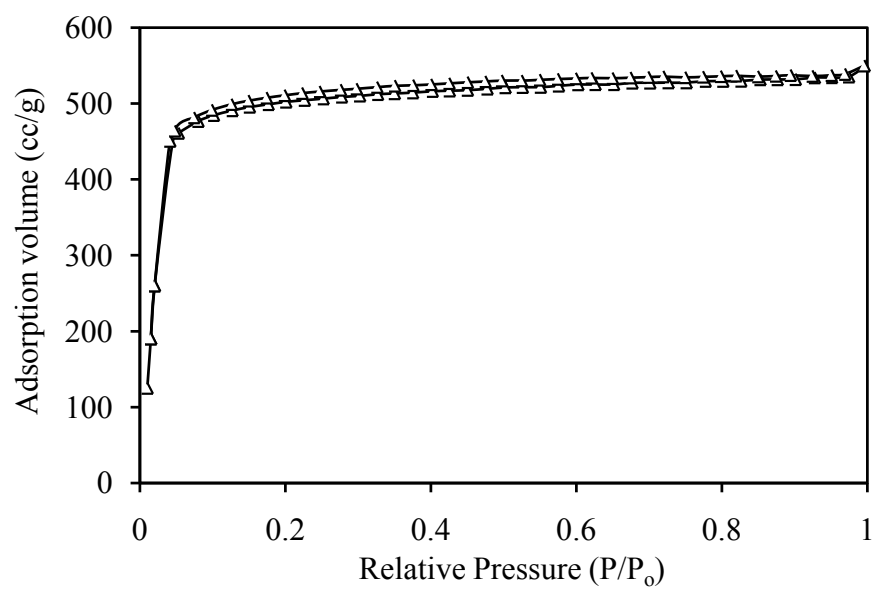

Figure 5. Nitrogen adsorption isotherm of the Porous carbon.

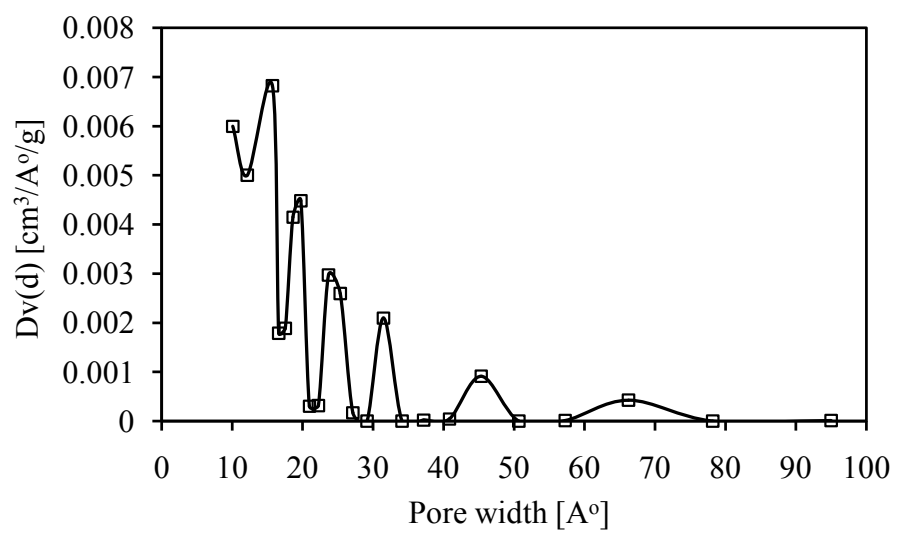

Figure 6. Differential pore size distribution of Porous carbon.

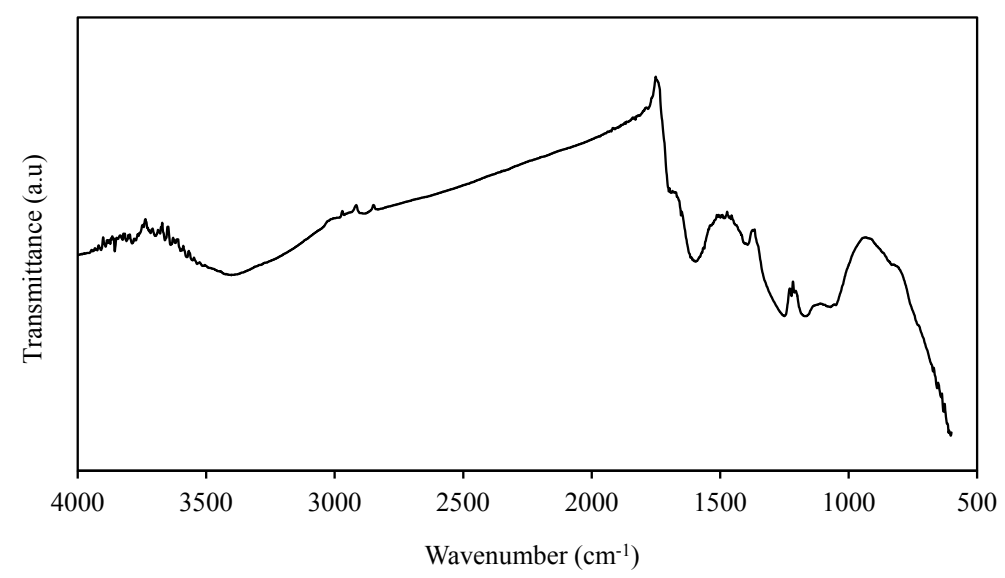

Figure 7. FT-IR of Porous carbon.

Table 8. Pore-structure parameters of porous carbon from petroleum coke.

\begin{tabular}{cccccc}
\hline Sample & $\begin{array}{c}\text { BET surface } \\
\text { area }\left(\mathrm{m}^{2} / \mathrm{g}\right)\end{array}$ & $\begin{array}{c}\mathrm{V}_{\mathrm{T}} \\
(\mathrm{cc} / \mathrm{g})\end{array}$ & $\begin{array}{c}\text { Micropore } \\
\text { volume \% }\end{array}$ & $\begin{array}{c}\text { Mesopore } \\
\text { volume \% }\end{array}$ & $\begin{array}{c}\text { Average pore } \\
\text { diameter }(\mathrm{nm})\end{array}$ \\
\hline $\begin{array}{c}\text { Petroleum } \\
\text { coke carbon }\end{array}$ & 2010 & 0.85 & 89.4 & 8.2 & 1.42 \\
\hline
\end{tabular}


olefin functional groups and the one at $1150 \mathrm{~cm}^{-1}$ to the stretching vibration of aromatic ring (methoxy-O- $\mathrm{CH}_{3}$ ) [10]. Peak $750 \mathrm{~cm}^{-1}$ pertain to $\mathrm{C}-\mathrm{H}$ out-of-plane bending in benzene derivatives [25].

The SEM image of porous carbon is shown in Figure 8, indicating presence of pores of different sizes on the surface of the carbon. A more intricate pore network inside the carbon could be envisaged with the larger pores acting as the main tributaries to the smaller pores inside. The cavities and pores were formed in the process of removal of activating agent and its derivatives from the carbon matrix during activation process. The white portions on the carbon surface could be possibly attributed to the presence of potassium residues [26]. The CHNS reports revealed that due to surface modifications occurred with $\mathrm{KOH}$ activation the elemental scenario in petroleum coke (C-85, H-2.1, N-1.5, S-5.2, O-6.2) to porous carbon (C-69.4, H-1.8, N-0.4, S-0.2, O-28.2).

\section{Conclusion}

Petroleum coke having low surface area $\left(11 \mathrm{~m}^{2} / \mathrm{g}\right)$ and pore volume $(0.012 \mathrm{cc} / \mathrm{g})$, was utilized to convert it into porous carbon with $\mathrm{KOH}$ activation using process optimization. An increase in the activation temperature, KPR and activation duration contributed to an increase in the BET surface area while the yield of porous carbon decreased. An increase in the activation duration was found to influence the BET surface area while its effect on the yield was found to be marginal. The optimum conditions have been identified to be an activation temperature of $639^{\circ} \mathrm{C}, \mathrm{KPR}$ ratio of 4.5 and duration of $43 \mathrm{~min}$, with the corresponding

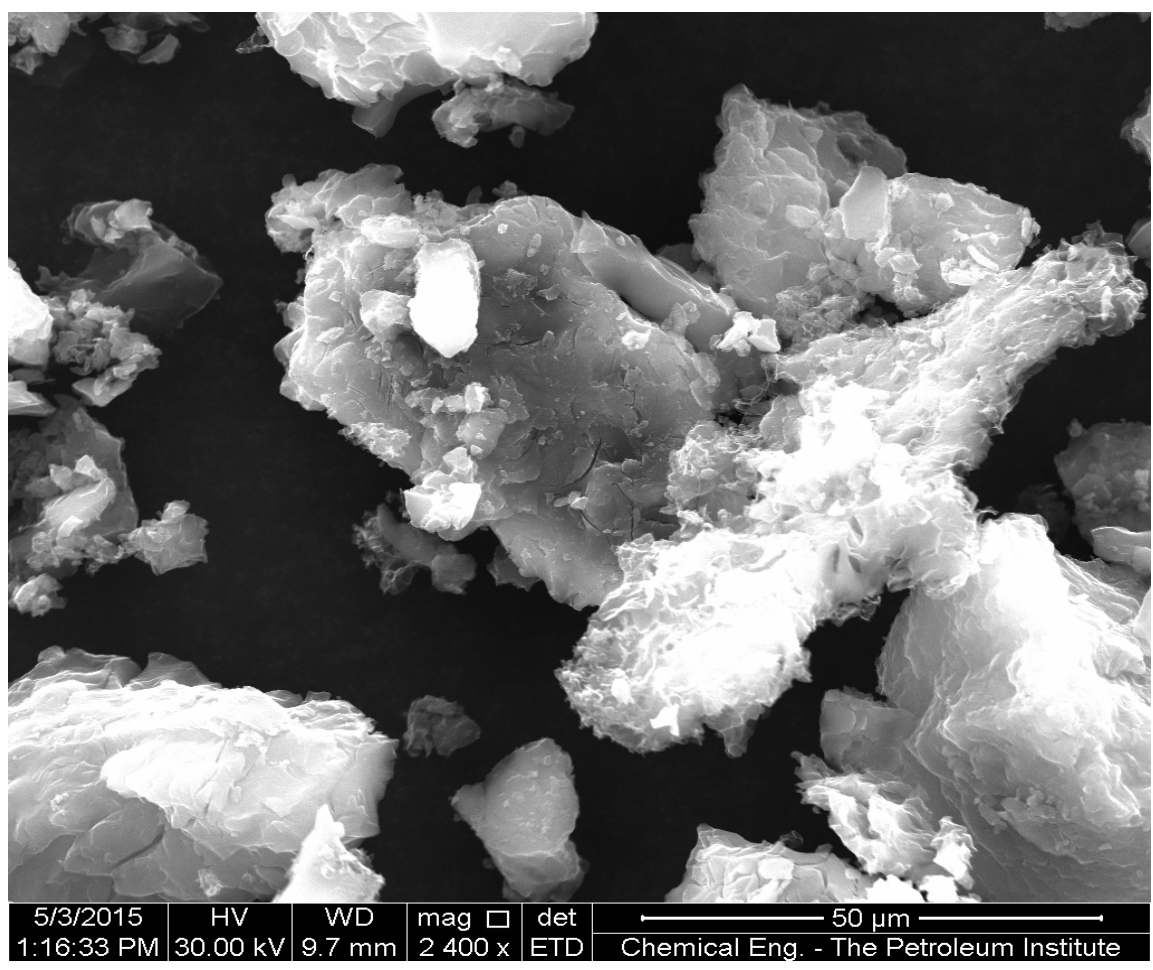

Figure 8. SEM image of porous carbon. 
BET surface area and yield being $1765 \mathrm{~m}^{2} / \mathrm{g}$ and $89.8 \%$. On the other hand, if the objective is restricted to maximize the BET surface area, an activation temperature of $688^{\circ} \mathrm{C}$, KPR of 3.8 and activation duration of $74 \mathrm{~min}$, results in a porous carbon with $2061 \mathrm{~m}^{2} / \mathrm{g}$ having an yield of 77\%. CHNS analysis of petroleum coke to porous carbon shows a good improvement in oxygen content from 6.2 to 28.2 and a drastic decrease in sulfur content from 5.2 to 0.2 , and improved physico-chemical properties.

\section{Acknowledgements}

The Authors wish to acknowledge the financial support from the petroleum Institute for giving an opportunity to work on Porous carbon development from petroleum coke (RIFP-15318/2015).

\section{References}

[1] Suresh Kumar Reddy, K., Shoaibi, A.A. and Srinivasakannan, C (2012) A Comparison of Microstructure and Adsorption Characteristics of Activated Carbons by $\mathrm{CO}_{2}$ and $\mathrm{H}_{3} \mathrm{PO}_{4}$ Activation from Date Palm Pits. New Carbon Mater, 27, 344-351. https://doi.org/10.1016/S1872-5805(12)60020-1

[2] Zhao, W., Fierro, V., Zlotea, C., Aylon, E., Izquierdo, M.T., Latroche, M. and Celzard, A. (2011) Optimization of Activated Carbon for Hydrogen Storage. Int J Hydrogen Energ, 36, 11746-11751. https://doi.org/10.1016/j.ijhydene.2011.05.181

[3] Sentorun-Shalaby, C., Ucak-Astalioglu, M.G., Artok, L. and Sarici, C. (2006) Preparation and Characterization of Activated Carbons by One Step Steam Pyrolysis/Activation from Apricot Stones. Micropor Mesopor Mater, 88, 126-134. https://doi.org/10.1016/j.micromeso.2005.09.003

[4] Hameed, B.H., Tan, I.A.W. and Ahmed, A.L. (2008) Optimization of Basic Dye Removal by Oil Palm Fiber-Based Activated Carbon Using Response Surface Methodology. J Hazardous Mater, 158, 324-332. https://doi.org/10.1016/j.jhazmat.2008.01.088

[5] Pinto, F., Lopes, H., Andre, R.N., Gulyurtlu, I. and Cabrita, I. (2008) Effect of Catalyst in the Quality of Syngas and By-Products Obtained by Co-Gasification of Coal and Wastes. 2: Heavy Metals, Sulphur and Halogen Compounds Abatement. Fuel, 87, 1050-1062. https://doi.org/10.1016/j.fuel.2007.06.014

[6] Marsh, H., Yan, D.S., O’Grady, T.M. and Wennerberg, A. (1984) Formation of Active Carbons from Cokes Using Potassium Hydroxide. Carbon, 22, 603-611. https://doi.org/10.1016/0008-6223(84)90096-4

[7] Raymundo-Pinero, E., Azais, P., Cacciaguerra, T., Cazorla-Amoros, D., Linares-Solano, A. and Beguin, F. (2005) $\mathrm{KOH}$ and $\mathrm{NaOH}$ Activation Mechanisms of Mutiwalled Carbon Nanotubes with Different Structural Organization. Carbon, 43, 786-795. https://doi.org/10.1016/j.carbon.2004.11.005

[8] Lee, S.H. and Choi, C.S. Chemical Activation of High Sulfur Petroleum Cokes by Alkali Metal Compounds. Fuel Process Technol, 64, 141-153. https://doi.org/10.1016/S0378-3820(00)00070-9

[9] Rambabu, N., Azargoha, R., Dalai, A.K. and Adjaye, J. (2013) Fuel Processing Technology. 106, 501-510. https://doi.org/10.1016/j.fuproc.2012.09.019

[10] Suresh Kumar Reddy, K., Shoaibi, A.A. and Srinivasakannan, C. (2012) Activated Carbon from Date Palm Seed: Process Optimization Using Response Surface Me- 
thodology. Waste Biomass Valor, 3, 149-156.

https://doi.org/10.1007/s12649-011-9104-4

[11] Lyubchik, S.B., Benoit, R. and Beguin, F. (2002) Influence of Chemical Modifications of Anthracite on the Porosity of the Resulting Activated Carbons. Carbon, 40, 1287-1294. https://doi.org/10.1016/S0008-6223(01)00288-3

[12] Hameed, B.H., Salman, J.M. and Ahmad, A.L. (2009) Adsorption Isotherm and Kinetic Modeling of 2, 4-D Pesticide on Activated Carbon Derived from Date Stones. $J$ Hazardous Mater, 163, 121-126. https://doi.org/10.1016/j.jhazmat.2008.06.069

[13] Gonen, F. and Aksu, Z. (2008) Use of Response Surface Methodology (RSM) in the Evaluation of Growth and Copper (II) Bioaccumulation Properties of Candida Utilis in Molasses Medium. J Hazardous Mater, 154, 731-738. https://doi.org/10.1016/j.jhazmat.2007.10.086

[14] Otowa, T., Tanibata, R. and Itoh, M. (1993) Production and Adsorption Characteristics of MAXSORB: High Surface Area Active Carbon. Gas Sep Purif, 7, 241-245. https://doi.org/10.1016/0950-4214(93)80024-Q

[15] Lillo-Rodenas, M.A., Cazorla-Amoros, D. and Linares-Solano, A. (2003) Understanding Chemical Reactions between Carbons and $\mathrm{NaOH}$ and $\mathrm{KO}$ : An Insight into the Chemical Activation Mechanism. Carbon, 41, 267-275. https://doi.org/10.1016/S0008-6223(02)00279-8

[16] Chiang, Y.-C., Chen, Y.-J. and Wu, C.-Y. (2017) Effect of Relative Humidity on Adsorption Breakthrough of $\mathrm{CO}_{2}$ on Activated Fibers. Materials, 10, 1296-1309. https://doi.org/10.3390/ma10111296

[17] Tan, I.A.W., Hameed, B.H. and Ahmad, A.L. (2008) Optimization of Preparation Conditions for Activated Carbons from Coconut Husk Using Response Surface Methodology. Chem Eng J, 137, 462-470. https://doi.org/10.1016/j.cej.2007.04.031

[18] Adinata, D., Daud, W.M.W.A. and Aroua, M.K. (2007) Preparation and Characterization of Activated Carbon from Palm Shell by Chemical Activation with $\mathrm{K}_{2} \mathrm{CO}_{3}$. Bioresource Technol, 98, 145-149. https://doi.org/10.1016/j.biortech.2005.11.006

[19] Zhao, W., Fierro, V., Zlotea, C., Aylon, E., Izquierdo, M.T., Latroche, M. and Celzard, A. (2012) Impact of Synthesis Conditions of KOH Activated Carbons on Their Hydrogen Storage Capacities. Int J Hydrogen Energy, 37, 14278-14284. https://doi.org/10.1016/j.ijhydene.2012.06.110

[20] Wang, H., Gao, Q. and Hu, J. (2009) High Hydrogen Storage Capacity of Porous Carbons Prepared by Using Activated Carbon. J Am Chem Soc., 131, 7016-7022. https://doi.org/10.1021/ja8083225

[21] Prahas, D., Kartika, Y., Indraswati, N. and Ismadji, S. (2008) Activated Carbon from Jackfruit Peel Waste by $\mathrm{H}_{3} \mathrm{PO}_{4}$ Chemical Activation: Pore Structure and Surface Chemistry Characterization. Chem Eng J, 140, 32-42. https://doi.org/10.1016/j.cej.2007.08.032

[22] Baquero, M.C., Giraldo, L., Moreno, J.C., Suraz-Garcia, F., Martinez-Alonso, A. and Tascon, J.M.D. (2003) Activated Carbons by Pyrolysis of Coffee Bean Husks in Presence of Phosphoric Acid. J Anal Appl Pyrol, 70, 779-784. https://doi.org/10.1016/S0165-2370(02)00180-8

[23] Hebeish, A., Ramadan, M.A., Abdel-Halim, E. and Abo-Okeil, A. (2011) An Effective Adsorbent Based on Sawdust for Removal of Direct Dye from Aqueous Solutions. Clean Techn Environ Policy, 13, 713-718.

https://doi.org/10.1007/s10098-010-0343-Z

[24] Salam, J.M., Njoku, V.O. and Hameed, B.H. (2011) Bentazon and Carbofuran Adsorption onto Date Seed Activated Carbon: Kinetics and Equilibrium. Chem Engg J, 
173, 361-368. https://doi.org/10.1016/j.cej.2011.07.066

[25] Guo, J., Luo, Y., Chong Lua, A., Chi, R., Chen, Y., Bao, X. and Xiang, S. (2007) Adsorption of Hydrogen Sulphide $\left(\mathrm{H}_{2} \mathrm{~S}\right)$ by Activated Carbons Derived from Oil-Palm Shell. Carbon, 45, 330-336. https://doi.org/10.1016/j.carbon.2006.09.016

[26] El-Hendawy, A.A. (2009) An Insight into the KOH Activation Mechanism through the Production of Microporous Activated Carbon for the Removal of $\mathrm{Pb}^{2+}$ Cations. Appl Surf Sci, 255, 3723-3730. https://doi.org/10.1016/j.apsusc.2008.10.034 